\title{
Investigação das espessuras das camadas de revestimento da rodovia BR-101, lote 07, trecho nordeste
}

\author{
Copyright 2016, SBGf - Sociedade Brasileira de Geofísica \\ Este texto foi preparado para a apresentação no VII Simpósio Brasileiro de Geofísica, \\ Ouro Preto, 25 a 27 de outubro de 2016. Seu conteúdo foi revisado pelo Comitê Técnico \\ do VII SimBGf, mas não necessariamente representa a opinião da SBGf ou de seus \\ associados. É proibida a reprodução total ou parcial deste material para propósitos \\ comerciais sem prévia autorização da SBGf.
}

Matheus Rodrigues Cunha* (IG/UnB), Welitom Rodrigues Borges (IG/UnB) e Luciano Soares da Cunha (IG/UnB)

\section{Resumo}

The Ground Penetrating Radar (GPR) was used to investigate a section of the highway BR-101, NE, Brazil. The method was chosen because of its characteristic of being non-destructive, attesting one of the its advantages. As the roads are composed of a number of horizontal layers, which thicknesses are specified in the construction project, the objective was to determine the thicknesses of some of these layers, the surface coarse and the base. Verifying the thicknesses was necessary to know if the layers were according to the project. In the surface coarse layer, the medium depth was shallower than the specified, where $78 \%$ of the $38.7 \mathrm{~km}$ analyzed presented small depth values.

\section{Introdução}

A malha rodoviária brasileira é muito extensa, abrange $1.691 .522 \mathrm{~km}$, dos quais $203.599 \mathrm{~km}$ são pavimentados e diversas dessas rodovias atravessam o Brasil de norte a sul. Porém ainda assim algumas regiões não possuem uma densa malha, fazendo com que o país ainda possua um grande potencial para obras de expansão das rodovias, como na última década, na qual houve um crescimento de $13,8 \%$ nos quilômetros de rodovias federais pavimentadas (CNT, 2014).

Antes da popularização e acessibilidade ao GPR os testes para que fossem verificadas as rodovias eram realizados de maneira direta, seja abrindo trincheiras ou fazendo um furo de sondagem. Apesar da obtenção da amostra, as opções causam danos a rodovia, prejudicam os usuários que trafegam pela rodovia, são caras e as informações obtidas são pontuais (Loizos e Plati, 2007). O primeiro GPR foi desenvolvido no final da década de 60 para fins militares na Guerra do Vietnã e desde a década de 70 tem sido utilizado para a verificação de rodovias (Morey, 1998).

O equipamento que compõe o GPR consiste basicamente de uma antena transmissora, uma antena receptora e uma unidade de armazenamento. A antena emissora envia ondas eletromagnéticas de alta frequência (entre 10 e $2500 \mathrm{MHz}$ ) que viajam pelo meio. O sinal refletido é então captado pela antena receptora (Reynolds, 1997; Borges, 2007). A gama de utilidades do método é bastante variada, com aplicações: geológicas, ambientais, engenharia, ciência forense, arqueológica, batimétrica, dentre outras ( Reynolds, 1997; Morey, 1998).
Para a construção de uma rodovia, diversos materiais são utilizados e dispostos em camadas horizontais. A camada mais externa, o revestimento, que tem por objetivo distribuir os esforços aplicados e resistir ao desgaste pela utilização. Abaixo dela, a camada de base, cuja função é redistribuir e também resistir aos esforços, é composta de macadame; por fim, a camada de sub-base, que é complementar a camada base e compostas de materiais como brita ou solo complementado com algum aditivo (DNIT, 2006).

A BR-101 é uma rodovia que atravessa doze estados brasileiros e possui uma extensão superior a $4.500 \mathrm{~km}$. Foi analisado no trabalho apenas o lote 07 do trecho nordeste, ao longo de aproximadamente $38,7 \mathrm{~km}$. O intuito do trabalho era verificar denúncias recebidas pela Advocacia Geral da União (AGU) de supostas irregularidades relacionadas ao projeto de construção da rodovia.

\section{Metodologia}

As ondas eletromagnéticas geradas pela antena transmissora viajam pelo meio a velocidades altas, cerca de $300 \mathrm{~km} / \mathrm{s}$. A onda que viaja pelo meio pode ser transmitida ou refletida quando atravessa interfaces. As reflexões são causadas pela mudança das propriedades entre os meios (Davis e Annan, 1989). As três principais propriedades utilizadas com método são: permissividade dielétrica $\varepsilon$, condutividade elétrica $\sigma$, e permeabilidade magnética $\mu$ (Beben, Mordak e Anigacz, 2012). O coeficiente de reflexão entre as interfaces pode ser calculado com a velocidade de propagação ou a permissividade dielétrica do meio (Equação 1). Para se obter a velocidade de propagação da onda eletromagnética em um meio onde não há grande perda de energia, utiliza-se a razão entre a velocidade da luz no vácuo $c$ e a raiz da permissividade dielétrica do meio $\varepsilon_{r}$ (Equação 2).

$$
\begin{gathered}
R=\frac{V_{2}-V_{1}}{V_{2}+V_{1}}=\frac{\sqrt{\varepsilon_{2}}-\sqrt{\varepsilon_{1}}}{\sqrt{\varepsilon_{2}}+\sqrt{\varepsilon_{1}}} \\
V_{m}=\frac{c}{\sqrt{\varepsilon_{r}}}
\end{gathered}
$$

As ondas são emitidas em uma certa frequência, porém durante o trajeto elas são atenuadas, especialmente as altas frequências (Neto e Medeiros, 2006). A atenuação depende do material ao qual o meio é composto, além da quantidade de água presente nesse meio (Leucci, 2008).

Os dados foram adquiridos utilizando uma antena de 900 $\mathrm{MHz}$, com common offset. No processamento dos dados utilizou-se o software Reflex-Win (Versão 6). 
No processamento usou-se um sequência (fluxograma) de filtros, ganhos e migração constante para todos os dados (Figura 1). Apesar de próxima, a antena do equipamento não ficou encostada ao chão, a primeira etapa consistiu na retirada no tempo de viagem entre a antena e o solo, fazendo com que a seção temporal se inicie na superfície. Para remover ruídos indesejados que podem causar interferência no sinal de interesse, aplicou-se um filtro passa-banda, retirando e atenuando as frequências fora da faixa de $900 \mathrm{MHz}$.

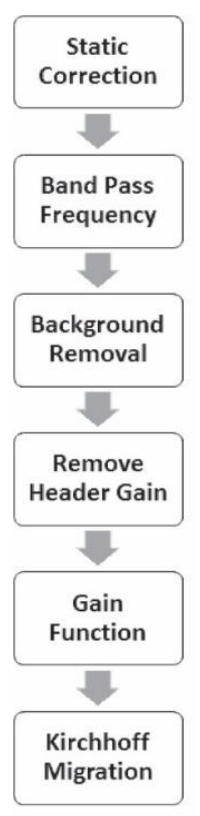

Figura 1 - Fluxo de processamento aplicado aos dados de GPR.

O sinal emitido está sujeito a interferências externas apesar da antena ser blindada, o que a protege de sinais advindos da superfície. O filtro passa-banda ajuda a retirar parte desse ruído, contudo, no dado também foi aplicada uma remoção de background para remover ruídos que são encontrados ao longo de toda a seção. Devido a atenuação que das ondas de acordo com que se afastam do emissor, perde-se energia e consequentemente amplitude do sinal. Retirando o ganho da primeira onda (header gain), para evitar problemas com escalas, foi aplicado um ganho linear combinado a um ganho exponencial, aumentando a amplitude do sinal do intervalo desejado. A aplicação da migração auxilia na definição das interfaces, movendo as reflexões para suas posições corretas. A migração de Kirchhoff foi aplicada aos dados para corrigir essas diferenças, melhorando as posições para que fossem realizadas as interpretações.

\section{Resultados}

A partir dos dados já processados, podem ser realizadas as análises em relação às camadas e propriedades do meio. Quando a onda encontra um obstáculo sem continuação lateral, ocorre uma difração. Na hipérbole gerada pela difração das barras de ferro no pavimento é ajustada uma curva corresponde, para que seja descoberta a velocidade de propagação. A abertura e comprimento da hipérbole são fatores que determinam a velocidade de propagação variável (Figura 2). Contudo essa velocidade não manteve-se constante ao longo de todo o trecho analisado, pois ocorreram chuvas, e a água é um fator que altera a velocidade de propagação.

De acordo com o projeto da rodovia, a camada de revestimento teria $22 \mathrm{~cm}$ de espessura, já a segunda camada ocorreria a uma profundidade de $32 \mathrm{~cm}$. Os valores médios de profundidade encontrados para a primeira camada e segunda camada foram de 20 e $32 \mathrm{~cm}$, respectivamente, o revestimento e a base (Figura 3 ).

Para delimitar as camadas, foram verificadas as difrações além do padrão seguido pela segunda camada. As marcações das camadas também podem ser feitas utilizado um traço $n$ do radargrama (Figura 4). A primeira camada, revestimento, é composta de concreto e

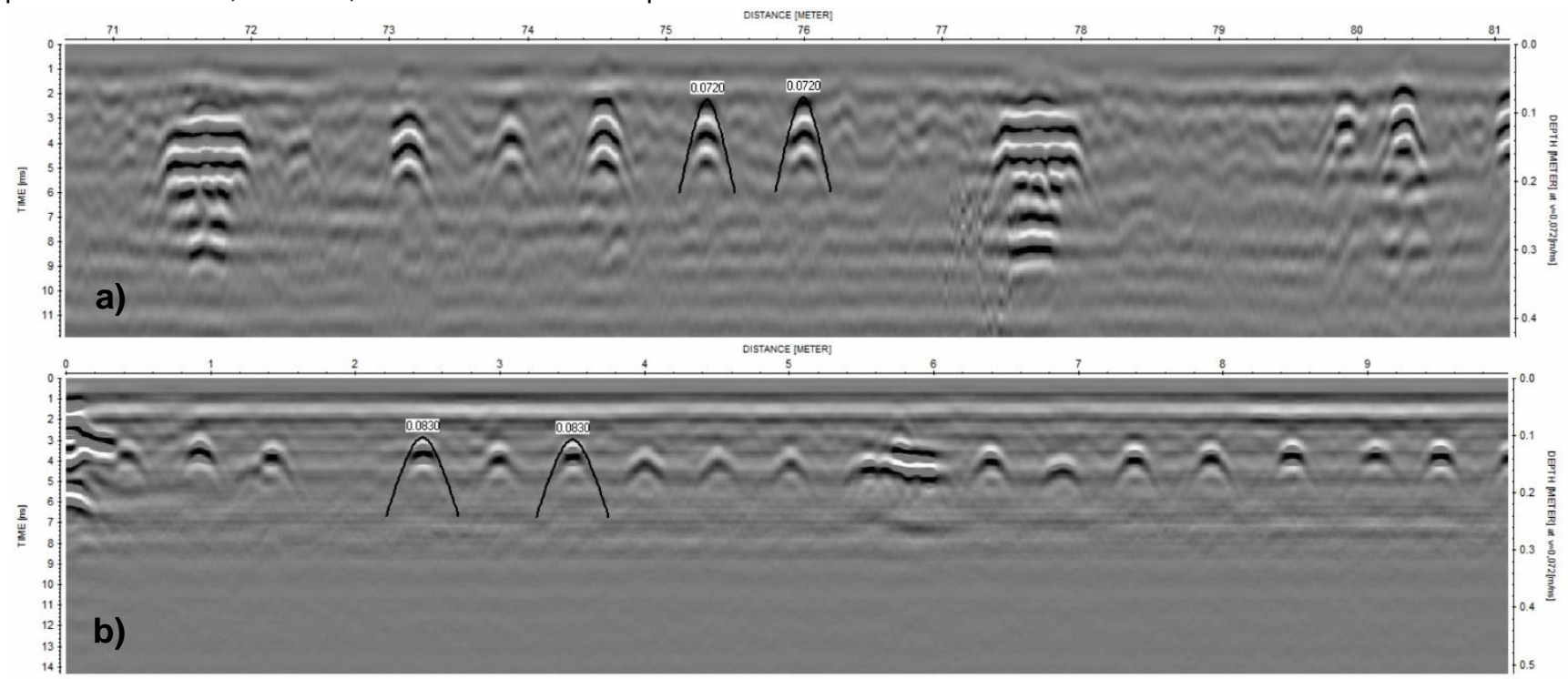

Figura 2 - Radargramas com hipérboles de ajuste de velocidade distintas sobrepostas a alvos hiperbólicos. a) velocidade de ajuste de $0,072 \mathrm{~m} / \mathrm{ns}$. b) velocidade de ajuste de $0,083 \mathrm{~m} / \mathrm{ns}$. 


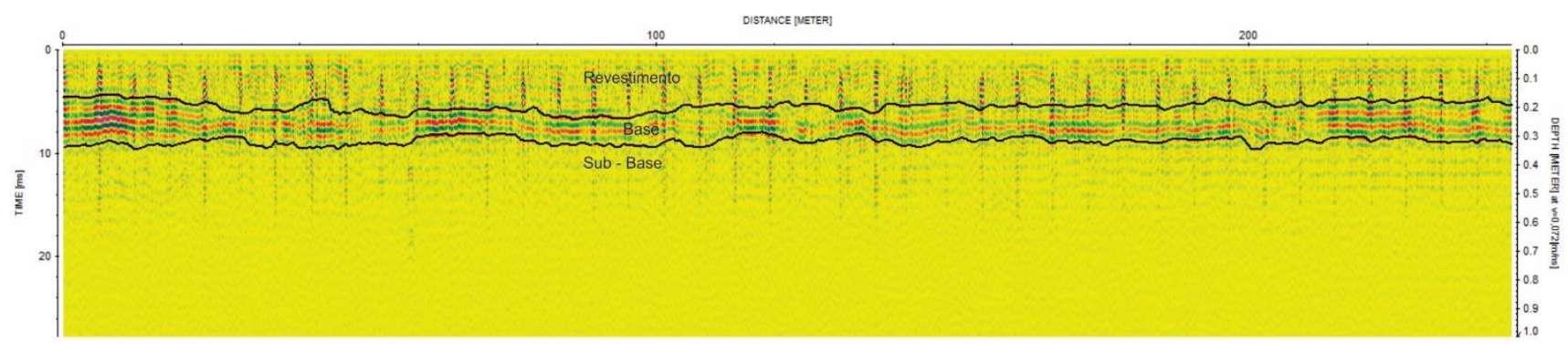

Figura 3 - Radargrama com os limites das interfaces entre as camadas de revestimento, base e sub-base.

apresenta uma espessura média de $20 \mathrm{~cm}$, e dentro dessa camada, existem barras de ferro que são utilizadas para dispersar a energia proveniente do tráfego de veículos entre as placas de concreto e se apresentam claramente no radargrama como difrações, as mesmas que foram utilizadas para o cálculo da velocidade de propagação. Já a segunda camada, base, possui uma espessura média de $12 \mathrm{~cm}$.

Os histogramas (Figura 5) mostram a distribuição das profundidades de marcação das camadas ao longo de toda a seção analisada. Cada coluna possui um intervalo de $1 \mathrm{~cm}$. As camadas apresentam irregularidades em muitos trechos, como mostram as Figuras 3 e 6 . Baseadas nas especificações do projeto, observa-se que as camadas são bastante irregulares, quando deveriam apresentar maior regularidade. As espessuras médias para a camada de revestimento e base foram de, respectivamente, 20 e $32 \mathrm{~cm}$. Contudo, do trecho total analisado, $78,76 \%$ da camada de revestimento estava com profundidades mais rasas, enquanto o mesmo índice foi de $50 \%$ para a camada de base.

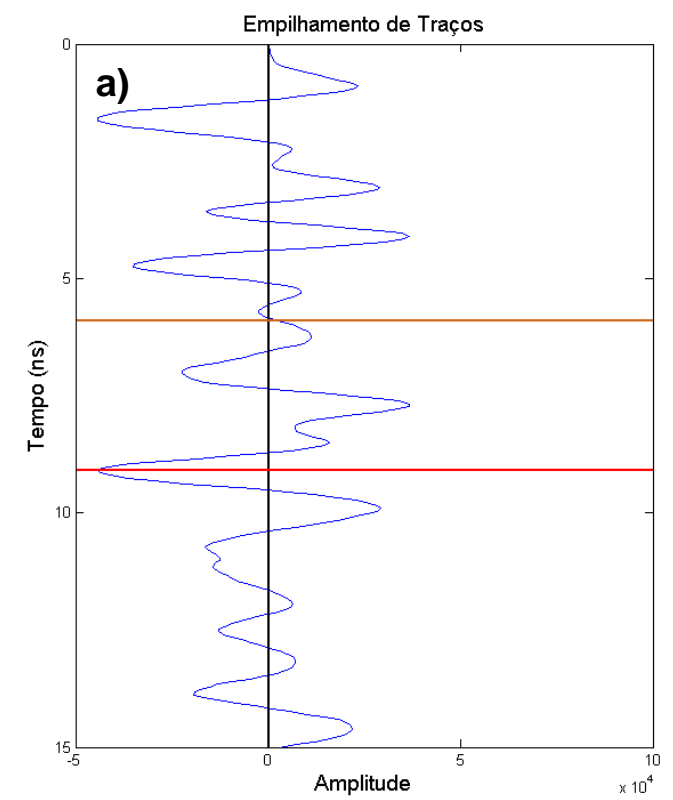

\section{Conclusão}

A aplicação do GPR como meio de observação indireta é bastante eficaz ao que se propõe, corroborado pelas décadas de uso. É possível identificar as camadas e suas delineações de topo e base enquanto o sinal apresenta amplitude suficientemente grande. Outra vantagem consiste no tempo de aquisição e custos. Devido à atenuação das ondas de alta frequência com o aumento da profundidade, como nesse caso, um processamento adequado é essencial. É possível perceber a irregularidade das camadas ao longo do trecho, como pode ser observado nos radargramas e histogramas, 0 que entra em desacordo com as especificações do projeto. Apesar de ambas as camadas apresentarem irregularidades, os dados da camada de base mostram que sua profundidade mesmo variando, oscila em torno do valor especificado no projeto, enquanto a camada de revestimento está majoritariamente mais rasa, e consequentemente, menos espessa.

\section{Agradecimentos}

Ao DNIT, pela cessão dos dados para que fosse realizado o projeto.

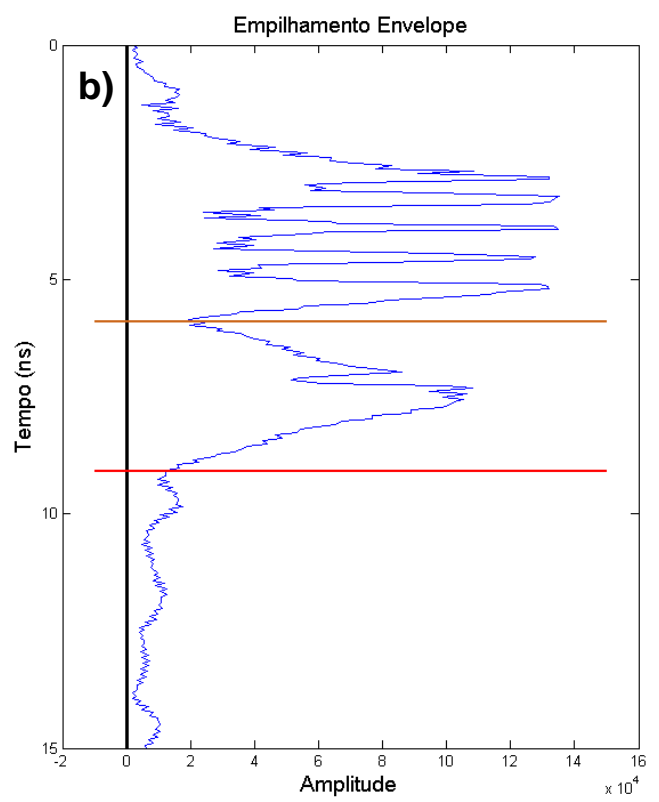

Figura 4 - Empilhamento de a) traços e b) envelope com as delimitações das interfaces entre as camadas de revestimento, base e sub-base. 

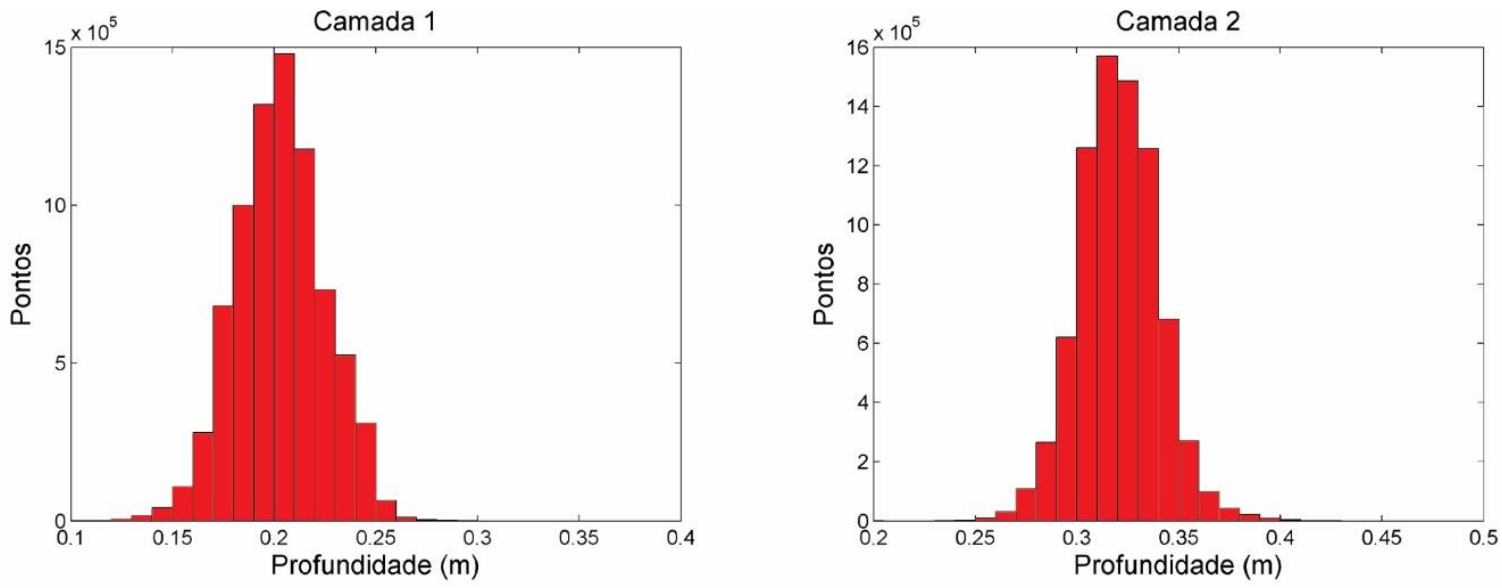

Figura 5 - Histograma com a distribuição das profundidades das camadas 1 e 2 , respectivamente, revestimento e base.

\section{Referências}

Beben, D., Mordak, A., e Anigacz, W. (2012). Identification of viaduct beam parameters using the Ground Penetrating Radar (GPR) technique. NDT\&E International, 49, 18-26.

Borges, W. R. (2007). Caracterização Geofísica de Alvos Rasos com Aplicações no Planejamento Urbano e Meio Ambiente : Estudo sobre o Sítio Controlado do IAG / USP. Universidade de São Paulo.

Confederação Nacional do Transporte - CNT. (2014). PESQUISA CNT DE RODOVIAS 2014 (Vol. 18). Brasília.

Davis, J. L., e Annan, A. P. (1989). Ground-Penetrating Radar for High-Resolution Mapping of Soil and Rock Stratigraphy. Geophysical Prospecting, 531-551.

Departamento Nacional de Infraestrutura de Transporte DNIT. (2006). Manual de pavimentação. Rio de Janeiro.
Loizos, A., e Plati, C. (2007). Accuracy of pavement thicknesses estimation using different ground penetrating radar analysis approaches. NDT and E International, 40(2), 147-157.

Morey, R. M. (1998). Ground penetrating radar for evaluating subsurface conditions for transportation facilities (Vol. 255). Transportation Research Board.

Neto, P. X., e de Medeiros, W. E. (2006). A practical approach to correct attenuation effects in GPR data. Journal of Applied Geophysics, 59, 140-151.

Reynolds, J. M. (1997). An Introduction To Applied And Environmental Geophysics (First edition). Chichester: John Wiley \& Sons Ltd.

Leucci, G. (2008). Ground Penetrating Radar: The Electromagnetic Signal Attenuation and Maximum Penetration Depth. Scholarly Research Exchange, 2008, $1-7$.

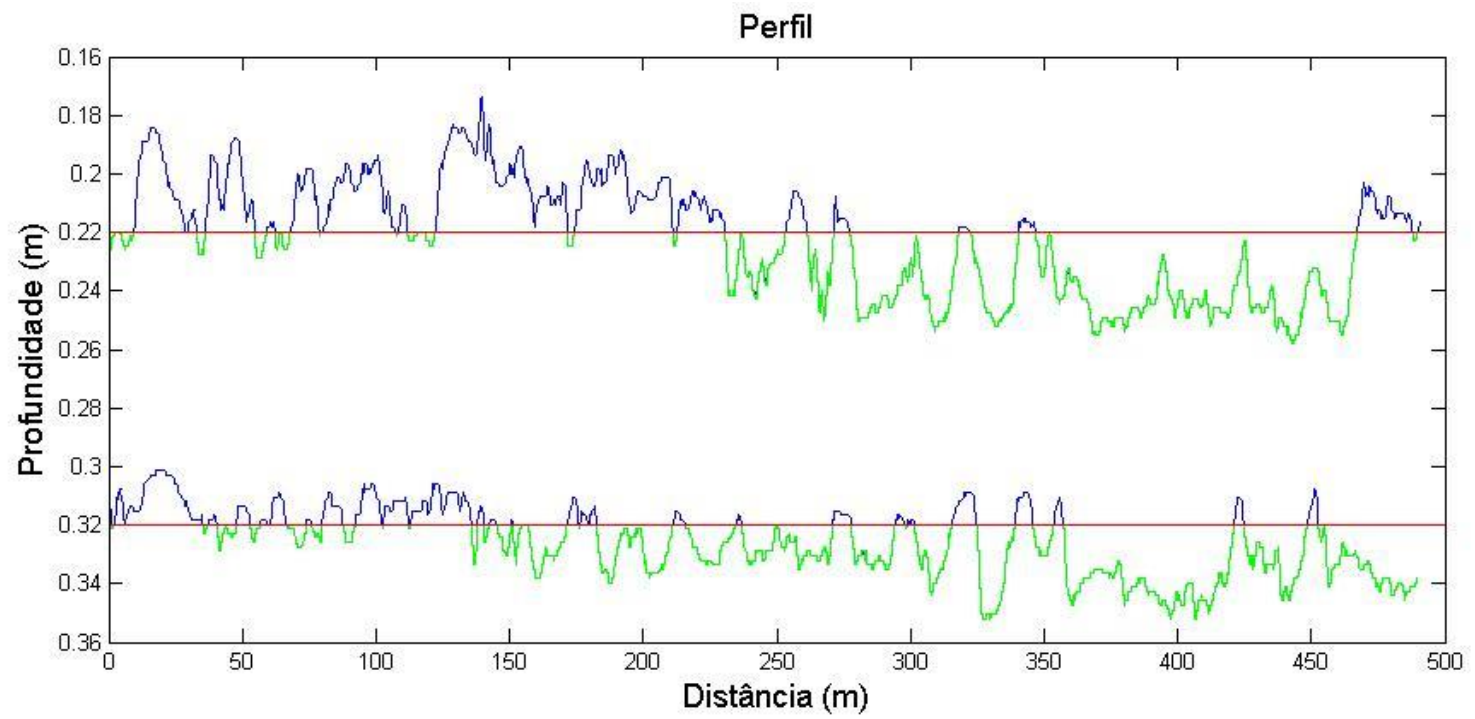

Figura 6 - Perfil de um trecho com as delimitações das profundidades do projeto, em vermelho, os valores azuis especificam onde a camada está mais rasa, e em verde onde está mais profunda. 